\title{
POTENCIAL DE MERCADO PARA IMPLANTAÇÃO DE UMA EMPRESA QUE SUBCONTRATA FRETE PARA ENTREGA DE PRODUTOS NO PONTAL DO PARANAPANEMA
}

\author{
Douglas Fernandes ${ }^{1}$, Flavio Alberto Oliva ${ }^{2}$, Valdinei Ribeiro da Silva \\ ${ }^{1}$ Faculdade de Tecnologia de Presidente Prudente - FATEC, Presidente Prudente, SP. ${ }^{2}$ Universidade do Oeste Paulista - \\ UNOESTE, curso de Engenharia de Produção, Presidente Prudente, SP. E-mail: douglas@hollosbdm.com.br; \\ flavioaoliva@gmail.com
}

\section{RESUMO}

O trabalho analisa a viabilidade mercadológica para instalação de uma empresa que forneça serviço subcontratado para terceirizar a logística de distribuição regional nos municípios compreendidos entre Pirapozinho e Rosana, rota conhecida como Pontal do Paranapanema no Estado de São Paulo. Por ser uma rota com baixo fluxo de entregas e quilometragem relativamente alta comparada a outros municípios, essas duas características são aspectos que impactam no prazo de entrega e nos custos operacionais. Por meio da pesquisa de mercado, constatou-se que existe, por parte das transportadoras, com sede em Presidente Prudente, interesse na formação de parcerias para viabilizar a rota e os custos.

Palavras-Chave: Mercado, Transporte, Subcontratação, Prazo de entrega

\section{MARKET POTENTIAL FOR THE IMPLANTATION OF A COMPANY THAT SUBCONTRACT FREIGHT FOR DELIVERY OF PRODUCTS IN THE PARANAPANEMA PONTAL REGION}

\begin{abstract}
The work analyzes the marketing feasibility for the installation of a company that provides subcontracted service to outsource regional distribution logistics in the municipalities between Pirapozinho and Rosana, a route known as Pontal do Paranapanema in the State of São Paulo. Because it is a route with low flow of deliveries and relatively high mileage compared to other municipalities, these two characteristics are aspects that impact on delivery time and on operating costs. Through the market research, it was verified that, on the part of the carriers, with headquarters in Presidente Prudente, there is interest in forming partnerships to make feasible the route and the costs.
\end{abstract}

Keyword: Market, Transportation, Subcontracting, Delivery time

\section{INTRODUÇÃO}

Quando a região do Pontal do Paranapanema, no Estado de São Paulo iniciou o desenvolvimento por meio das ferrovias na década 1950, houve grande expectativa de crescimento, visto que a proposta de integração com a cidade de Dourados, no Estado do Mato Grosso do Sul alteraria de forma positiva o cenário do transporte de bens materiais e passageiros na região. Porém, o projeto não foi concluído e para agonia no final na década de 1980 o transporte de passageiros ficou deficitário e a gestão ferroviária acoplava vagões destinados aos passageiros a vagões de cargas.

Atualmente o sistema rodoviário se tornou o principal meio de transporte para a região do Pontal do Paranapanema, onde empresas transportadoras e distribuidoras oferecem serviços de entregas concorrendo entre si, gerenciando ou, muitas vezes, amargando a ociosidade de veículos e os custos destes. 
Nesse contexto, uma das preocupações dos gestores é equilibrar o nível de serviço com os custos, sem perder de vista a satisfação dos clientes. Logo, estar atento aos índices de custos e qualidade no transporte de suas mercadorias, requer sempre atenção especial devido ao impacto direto que esses causam na formação do preço e na disponibilidade dos produtos nas prateleiras.

Quando o transporte é a atividade principal de uma organização, controlar este custo e garantir a qualidade do serviço é vital para competir no mercado. Uma das combinações para o sucesso do negócio é ter fluxo de carga que minimize ociosidade dos veículos de entrega, gerando maior intensidade de atendimento das rotas e como consequência melhor prazo de entrega.

O desafio dos gestores é ainda maior quando a empresa de transporte atua em regiões que combinam cidades com histórico de baixa movimentação de mercadorias e alta quilometragem entre si, comparada a outras rotas regionais. A concorrência do setor de transporte rodoviário de cargas contribui, ainda para que este já baixo fluxo de encomendas seja dividido entre os concorrentes que oferecem serviços naquela região. Na prática, o que se verifica são empresas que disponibilizam veículos com sua capacidade de carga ociosa para realizar entregas em uma cidade no final de uma rota, no caso deste artigo, cidades da região do Pontal do Paranapanema.

O presente artigo tem como objetivo analisar a viabilidade mercadológica para instalação de uma empresa de logística de distribuição, que presta serviços subcontratados, que possa unificar todo o baixo fluxo de encomendas, potencializando a capacidade de carga de equipamentos, reduzindo o custo de entregas e reduzindo o prazo de entregas de encomendas direcionadas a municípios da região do Pontal do Paranapanema, partindo de uma base instalada em Presidente Prudente-SP.

\section{METODOLOGIA}

A metodologia adotada no presente trabalho partiu da compreensão desta como a aplicação da inteligência com objetivo de definir um conjunto de técnicas para alcançar um entendimento lógico sobre algo, logo um método, que não está isento de erro. Todas essas técnicas em conjunto, formam uma estrutura para ser aplicada no desenvolvimento de um trabalho (SCHLITTLER, 2015).

Nesse contexto, o estudo partiu da definição de um nível de serviço a ser oferecido em uma rota, associada ao custo e demanda, apurados por meio de pesquisa de mercado.

\section{MÉTODOS E RESULTADOS}

"Serviços constituem uma transação realizada por uma empresa ou por um indivíduo, cujo objetivo não está associado à transferência de um bem". (LAS CASAS, 2012, pag. 6).

"De certa forma, o serviço se diferencia do produto pela sua intangibilidade, ou seja, não pode ser tocado, armazenado. O serviço proporciona lembranças". (COBRA, 2009, pag.216).

O setor de atuação da atividade em análise apresenta-se como de serviços de transporte de mercadorias. Por ser um produto intangível, à apresentação de relatórios de desempenho são úteis para sua melhor mensuração e percepção de sua realização.

O serviço de transporte rodoviário de carga pode ser realizado por meio de carga consolidada, bem como fracionada, podendo este serviço ser contratado com formação de parceria, ou seja, contrato de serviço periódico ou por meio de atendimento eventual.

No que tange ao potencial e vantagens competitivas para mensuração da logística de resultados para a rota "Pontal do Paranapanema", discutida neste trabalho, destaca-se a importância da oferta de uma estrutura e expertise em serviço de armazenagem de cargas, agendamento de entregas e administração de ocorrências que parceiros e clientes defrontam no cotidiano para descarregarem suas mercadorias, ocasionando tempo não útil na aplicação de 
recursos. Esses serviços convertem-se em potencial competitivo para os usuários que poderão utilizar em planejamento estratégico, conforme comungado abaixo.

"[...] o posicionamento competitivo refere-se fazer escolhas que resultem em um ajuste perfeito entre os alvos de mercado escolhido e as competências e ativos que a empresa pode acionar para atender a esses alvos com mais eficácia do que seus concorrentes" (Graham Hooley, Nigel F. Piercy, Brigitte Nicoulaud, 2011, pag. 390).

E ainda.

"O desenvolvimento de novos produtos se concentra na descoberta de novas maneiras de solucionar os problemas do cliente e criar experiências mais satisfatórias para ele" (PHILIP KOTLER, GARY ARMSTRONG, 2007, pag. 240).

O público alvo é composto por transportadoras que possuem unidades na cidade de Presidente Prudente, distribuidores, indústria e comércio que movimentam mercadorias fracionadas na região de atuação, e toda empresa logística que chega e faz uso das condições do município de Presidente Prudente para distribuição na região através de transporte rodoviário de cargas. A fundamentação pela busca deste público alvo encontra-se no seguinte pensamento: "Os segmentos escolhidos são chamados de mercado alvo. É todo aquele mercado em que você deseja focar sua ação" (LAS CASAS, 2011, pag. 85).

Uma característica comum desses potenciais clientes, é agir individualmente para atender suas entregas na região do Pontal do Paranapanema, seja por meio de frota própria ou por agregados subcontratados. Dessa forma, visando reduzir custos por conta do baixo volume, acabam por acumular cargas para formar um fluxo que equilibre os custos, tendo como consequência o aumento no prazo das entregas, reduzindo assim o nível de serviço logístico.

Assim também poderá ocorrer com as indústrias e comercio que não utilizam transportadores para efetuar a distribuição de suas mercadorias, não tendo um fluxo de entrega que viabilize a operação, o que acaba por prolongar o prazo de entrega, afim de formar um fluxo de entrega, porém assumindo os custos da operação.

A área a ser prestado os serviços em discussão compreende o município de Presidente Prudente e os municípios da rota denominada Pontal do Paranapanema que tem uma quilometragem prevista de $210 \mathrm{~km}$ para ser percorrida.

Figura 1 - Mapa da região de atuação

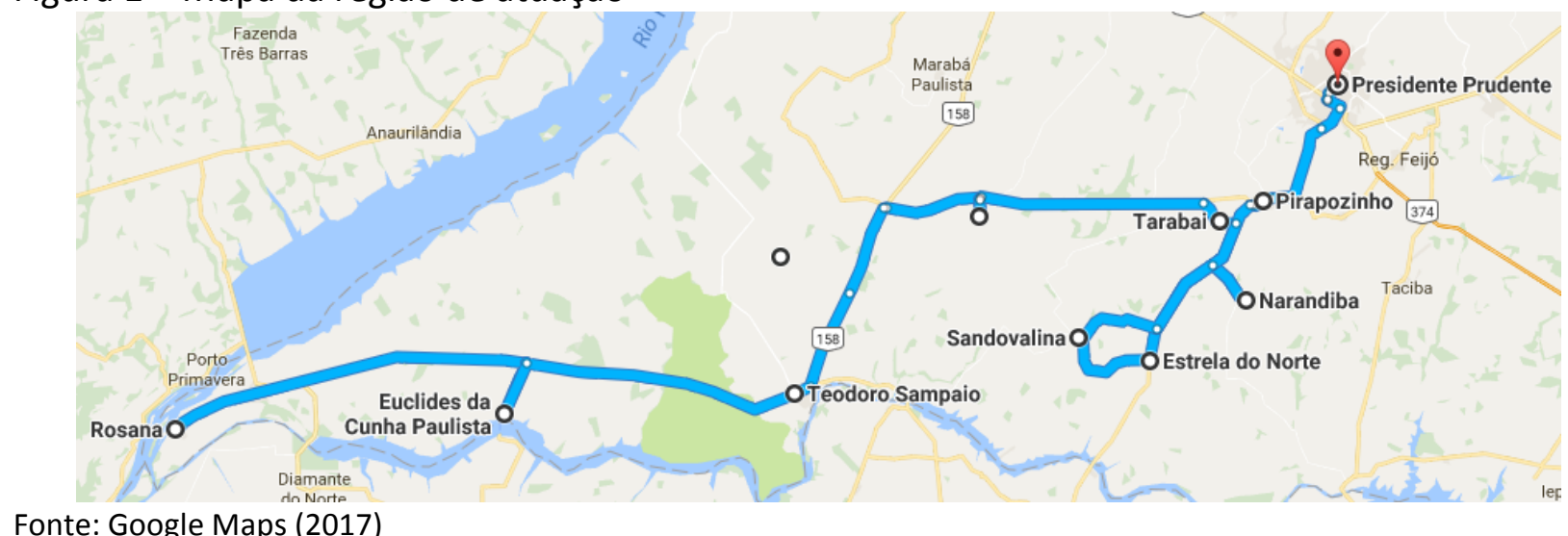

De acordo com SCHLITTLER (2015, pag. 60), reflete-se que:

Os estudos realizados por meio de pesquisa de campo caracterizam-se pela observação controlada, pela utilização de técnicas de amostragem, coleta de dados e mensuração, com a finalidade de analisar a ocorrência de variáveis e definir conclusões relativas ao fenômeno observado. Resumidamente, a pesquisa de campo é desenvolvida pela observação 
direta intensiva, caracterizada pela observação genérica e pela prática de entrevistas.

Nesse sentido, foi elaborado questionário visando aprofundar o conhecimento desse mercado e sobre possível tendência para subcontratação de serviços logísticos para a rota do Pontal do Paranapanema, sendo estes aplicados em um universo composto pelas principais empresas de cargas e encomendas da cidade de Presidente Prudente, que atualmente atendem a região em estudo, que tabulados apresentam os seguintes resultados:

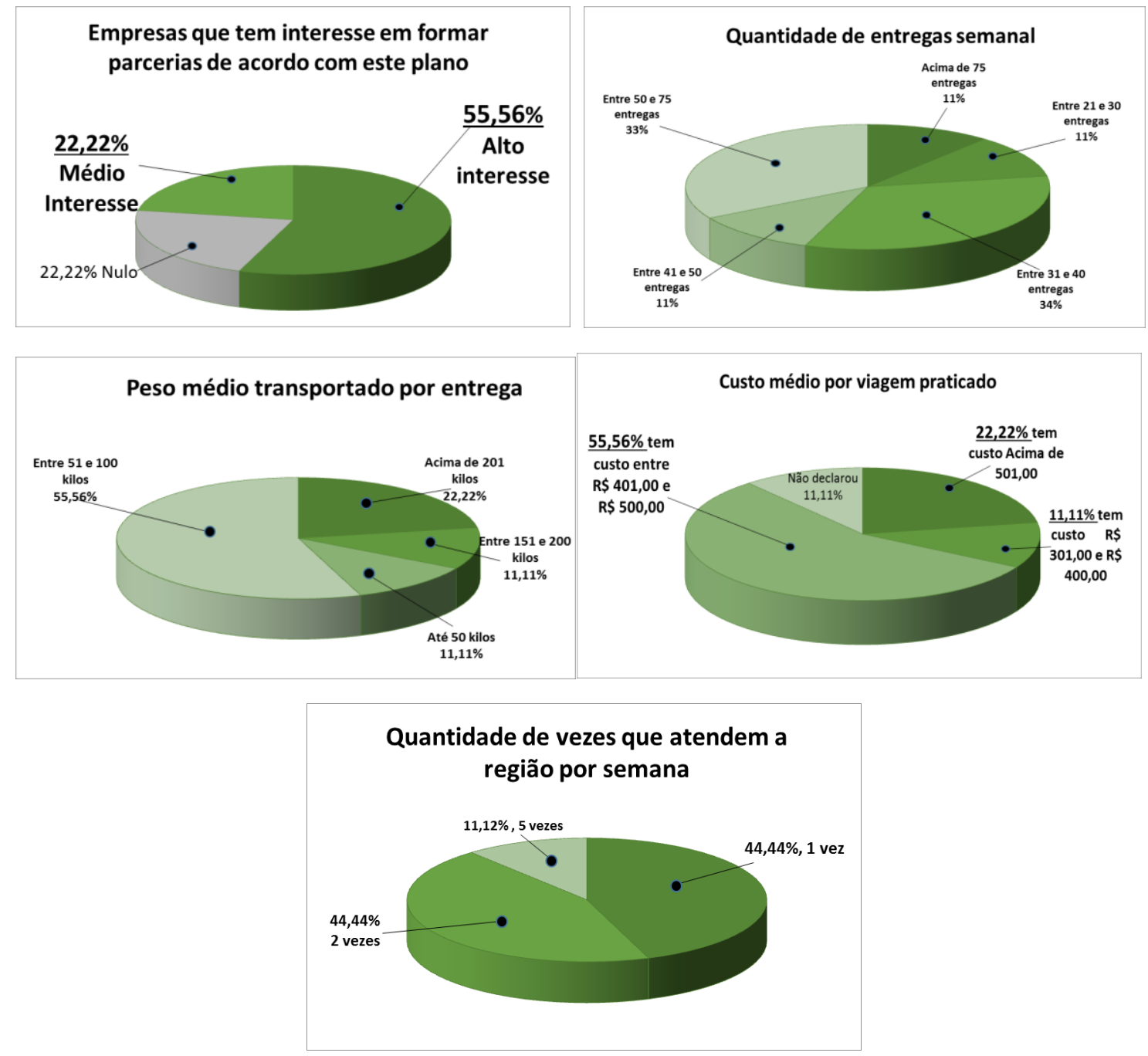

\section{DISCUSSÃO}

A pesquisa demonstra que $55,56 \%$ dos entrevistados têm alto interesse em subcontratar empresa para atender a rota, e $22,22 \%$ têm interesse médio, e por fim os $22,22 \%$ restantes no momento não estão propensos a subcontratar empresas para terceirizar seus serviços, segundo informaram os gestores, os maiores motivos para essa não propensão, estão ligados à falta de uma proposta concreta a ser analisada pela diretoria e não dispor do serviço visto ser um complemento de faturamento devido ter outras atividades na região.

No que tange às quantidades de entregas semanais, projeta-se uma média de 440 entregas por semana. No entanto, três empresas consideráveis no universo das empresas que atuam no segmento de transporte de cargas e encomendas na região de Presidente Prudente não responderam esta pesquisa devido a questões de política interna. Porém, tais empresas já 
praticam a terceirização com agregados, o que permite enquadrá-las como clientes potenciais para o tipo serviço em análise.

Quanto ao custo médio por viagem, $55,56 \%$ das empresas apresentam custo entre R\$ 401,00 até $\mathrm{R} \$ 500,00,11,11 \%$ apresenta o custo entre 301,00 até 400,00 e constatamos que $22,22 \%$ tem um custo acima de 501,00 , e por fim $11,11 \%$ optou por não declarar.

Das empresas entrevistadas, $88,88 \%$ atendem no máximo 2 vezes por semana a rota em análise, o que demonstra que a possibilidade de oferta de um número maior de dias para atendimento da rota, por um custo inferior ao atualmente praticado pelas empresas alvo, torna o projeto atrativo em termos mercadológicos.

\section{CONCLUSÃO}

A pesquisa de campo permitiu uma melhor compreensão da realidade do mercado de transporte rodoviário de cargas, seguimento de encomendas fracionadas, de forma a concluir que: a) existe demanda potencial para a oferta do serviço proposto; b) existe interesse pelo serviço; $c$ ) existe margem para melhorar o nível de serviço no que tange o prazo de entrega.

\section{REFERÊNCIAS BIBLIOGRÁFICAS}

COBRA, Marcos. Administração de Marketing no Brasil. 3. Ed. Rio de Janeiro, Elsevier, 2009.

CHRISTOPHER, Martin. Logística e Gerenciamento da Cadeia de Suprimentos. 3. Ed. São Paulo. Cengage Learning, 2011.

FARAH, Osvaldo Elias; CAVALCANTI, Marly; MARCONDES, Luciana Passos Marcondes. Empreendedorismo Estratégico: Criação e gestão de pequenas empresas. São Paulo: Cengage Learning, 2015.

GUIA DO TRANSPORTADOE DE CARGA: Indicadores de Desempenho em Logística. Disponível em < http://www.guiadotrc.com.br/logistica> Acesso em 03/06/2017.

HOOLEY, Graham; PIERCY, Nigel F; NICOULAUD, Brigitte. Estratégia de Marketing e Posicionamento Competitivo. 4. Ed. São Paulo: Pearson, 2011.

IRELAND, R. Duane; HOSKISSON, Robert E; HITT, Michael A. Administração Estratégica. 10. Ed. São Paulo: Cengage Learning, 2014.

KOTLER, Philip; ARMSTRONG, Gary. Princípios de Marketing. 12.Ed. São Paulo: Pearson, 2007.

KOTLER, Philip; KELLER, Kevin Lane. Administração de Marketing: A bíblia do marketing. 12. Ed. São Paulo: Pearson, 2006.

LAS CASAS, Alexandre Luzzi. Marketing de Serviços. 6. Ed. Atlas, São Paulo, 2012.

LAS CASAS, Alexandre Luzzi. Plano de Marketing para micro e pequena empresa. 6. Ed. São Paulo: Atlas, 2011.

MARRAS, Jean Pierre. Administração de Recursos Humanos: Do Operacional ao Estratégico. 14. Ed. São Paulo: Futura, 2011. 
MARTINELLI, Fernando Baracho. Qualidade: Fundamentos e Processos. 1. Ed. Curitiba: lesde, 2009.

SLACK, Nigel; CHAMBERS, Stuart; JOHNSTON, Robert. Administração da Produção. 2. Ed. São Paulo: Atlas,2008.

OLIVEIRA, Djalma de Pinho Rebouças de. Planejamento Estratégico: conceitos, metodologia e práticas. 30. Ed. São Paulo: Atlas, 2012.

OLIVEIRA, Djalma de Pinho Rebouças. Sistemas, organização \& métodos. 20. Ed. São Paulo: Atlas, 2011. 